\title{
EFFECTIVENESS OF THE NON-PROFIT ORGANISATION, 'GRANDMOTHERS AGAINST POVERTY AND AIDS’ - A STUDY
}

\author{
Kathleen Brodrick, $M S_{c}$ OT, Director, GAPA \\ Mandisa Mafuya, $B A$, Project Manager, GAPA \\ Grandmothers Against Poverty and AIDS, Khayelitsha, W Cape
}

\begin{abstract}
Arising out of and based on a pilot intervention project of the Albertina and Walter Sisulu Institute of Ageing in Africa, a nonprofit organisation called Grandmothers Against Poverty and AIDS (GAPA) was formed.

GAPA has been operating in Khayelitsha since October 2001. In that time the number of grandmothers participating in GAPA activities, namely workshops and psychosocial support groups, has been growing steadily. Anecdotal evidence suggests that the grandmothers are developing the capacity to cope with the effects of the AIDS crisis and are becoming empowered members of their communities.
\end{abstract}

The intervention strategy of GAPA is a two-pronged approach. Firstly grandmothers are invited to attend a workshop series which cover topics such as AIDS education, home care, nutrition, elder abuse, human rights, food gardening, drawing up wills, accessing social grants and business skills. These workshops are for a maximum of 30 grandmothers and are held over 3 days each month. The workshop facilitators are local experts in their field and some are grandmothers who have been trained by GAPA. All workshops are conducted in the local language, isiXhosa. Since May 2002, 250 grandmothers have attended a series of workshops at some time. The number of grandmothers attending continues to grow by 30 each month.

The second approach has been to invite grandmothers who are directly affected by HIV/AIDS in their families to join a support group in their neighbourhood. The support groups, consisting of between 5 and 10 members, are activity-based. Meetings are held in group leaders' homes once a week. Education, problem solving and handicraft manufacture is carried out in the groups. The groups form autonomous units under the guidance and leadership of the group leader.

Home groups as a support strategy were started in July 2002 to accommodate the growing number of grandmothers who wanted to join the existing psychosocial support group. Grandmothers who had been trained in the pilot intervention phase held between August and November 2001, had developed sufficient confidence in their own knowledge of HIVIAIDS and handicraft skills to lead others. An added benefit of the home groups was the eradication of the problem of transport costs incurred by grandmothers getting to the venue. Setting up groups in their neighbourhoods meant that grandmothers could now walk a short distance to attend their group. The logistical problems of feeding a growing and fluctuating number of attendees were also removed with the formation of home groups. The group leaders were given a cash allowance to provide food for the groups from their kitchens.

In July 2002 there were 3 groups. This grew to 6 by August 2002 and to 9 by February 2003. In July 2003 there were 12 groups. Monitoring of the groups began in earnest in July 2003 with the employment of a project manager. Continuous monitoring of the groups led to the eradication of fictitious attendance books and the dissolution of one group. With the improved system, new groups were formed in new areas and some new group leaders were brought on board. In February 2004 there were 13 groups led by 8 group leaders. In December 2004 there were 19 groups held in 6 suburbs of Khayelitsha and run by 13 group leaders. Three groups were formed in the Eastern Cape in November 2003.

\section{THE STUDY}

In order to evaluate the effectiveness of GAPA's presence as an agent in the fight against poverty and AIDS in grandmotherheaded households in Khayelitsha, a qualitative and quantitative study was conducted from July 2004 to December 2004.

\section{INSTRUMENTS}

A questionnaire was administered to all grandmothers who attended one of the home support groups. Items on the questionnaire covered demographic details of the group 
attendee, her family's status with regard to HIV/AIDS, the number of grandchildren living with her, details of membership of GAPA, and economic gains as a member. Additional items asked respondents to articulate what the best and the worst aspects of belonging to a group were. The questionnaire was administered in isiXhosa or English, and was completed by 163 grandmothers.

The second investigation was a phenomenological study investigating the meaning of membership of GAPA and how this membership had impacted on grandmothers' lives. In order to elicit the meaning of membership of GAPA, an 'indaba' was held each month to which all group members were invited. The sampling method was that of voluntary participation. Provision was made in the programme of events for grandmothers who wished to participate to address the gathering about what being a member of GAPA had meant to them.

\section{RESULTS AND DISCUSSION}

\section{AGES OF GROUP MEMBERS}

Ages of GAPA members ranged from 40 to 90 years $(N=163)$. The age distribution is shown in Fig. I.

Membership of GAPA is defined as grandmothers aged 50 years and older. Of the respondents, 45\% were aged 60 years and older. At 60 women are eligible for social assistance of R740 per month. Eighteen per cent of the group members were aged between 40 and 49 years. In these cases the group leaders had used their judgement and allowed the younger women to join because they were grandmothers and were in need of psychosocial support. Thirty-seven per cent of the grandmothers were aged between 50 and 59 years.

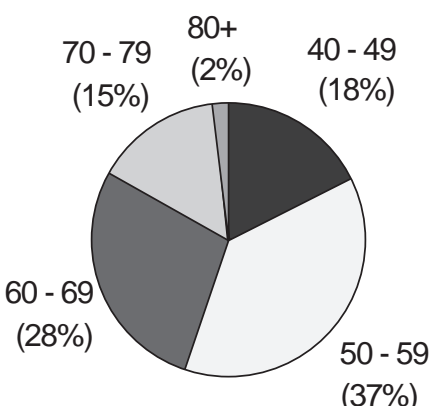

Fig. 1. Group membeers by age.

\section{HIV-INFECTED GRANDMOTHERS}

Eight respondents reported that they were HIV positive. These grandmothers were aged 42,44, 47, 50, 51 (2), 56 and 57 years. In all, these 8 women cared for 24 children under the age of 21 years, 12 of whom were grandchildren. One of the 51-year-old grandmothers cared for 7 children under the age of 21 years, 3 of whom were grandchildren. Only 1 of the grandmothers (one of the 51-year-olds) had a cohabiting husband who was also HIV positive.

\section{RECENT DEATHS}

Of the grandmothers $82 \%$ reported that they had experienced recent deaths in their families (Fig. 2). Deaths were considered to be recent if they had occurred within the last 5 years and were still a source of sorrow for the participant. Causes of death were not specifically asked about. However, most deaths were thought by the subjects to be the result of opportunistic diseases due to AIDS. Some participants indicated that at the time of the death they were unaware of HIVIAIDS and in hindsight realised that HIV infection had been the root cause of the person's untimely death.

\section{FAMILY HIV STATUS}

The respondents were asked if they knew any family members who were HIV positive, and 64\% reported that they had living family members who were known to be HIV positive (Fig. 3).

\section{CHILDREN WHO LIVE WITH GRANDMOTHERS}

One hundred and fifty-five respondents reported that children under the age of 21 years lived in their homes. These respondents cared for a total of 515 children, of whom 366 were grandchildren. The other 149 children were either their own children, foster children or children of close relatives for whom they were responsible.

\section{BENEFITS RECEIVED DUE TO GAPA MEMBERSHIP}

In response to the question 'Have you made any money for yourself from being a member of GAPA?' 65\% of respondents said that they had made some money. Responses were vague, ranging from 'a little' to 'a lot'. In less than $23 \%$ of cases was an actual monetary value given. Two respondents were definite that they made R100 and R25 per month, respectively. The range was from R10 to R2000. Others who gave a monetary value did not specify over what time period they had made the money.

Of the grandmothers 64\% reported that they had benefited from being a member of GAPA by receiving school fees (81\%) and food (57\%). Four respondents said that they had received materials with which to do handicraft. However, all grandmothers received fabric and other handicraft materials in their groups as well as a meal.

\section{WHAT GRANDMOTHERS HAD LEARNED AS MEMBERS OF GAPA}

All participants reported that they had learned something from being involved with GAPA. The responses fell into the following categories:

- Acceptance - 'To be able to help a person with HIV and to teach others how to accept them.

- Home nursing - 'You can support the HIV positive person without becoming sick.

- Practical skills - 'How to grow vegetables and how to sew' 


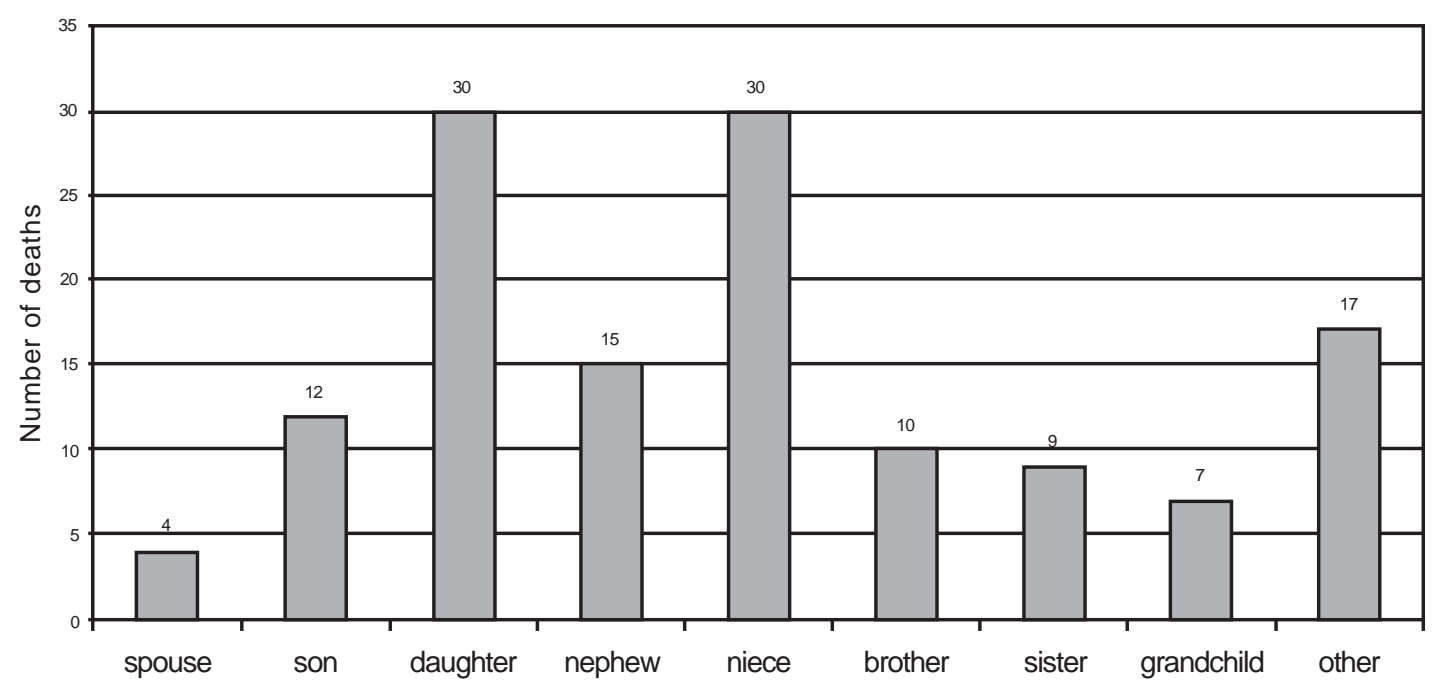

Fig. 2. Grandmothers' family members who had recently died.

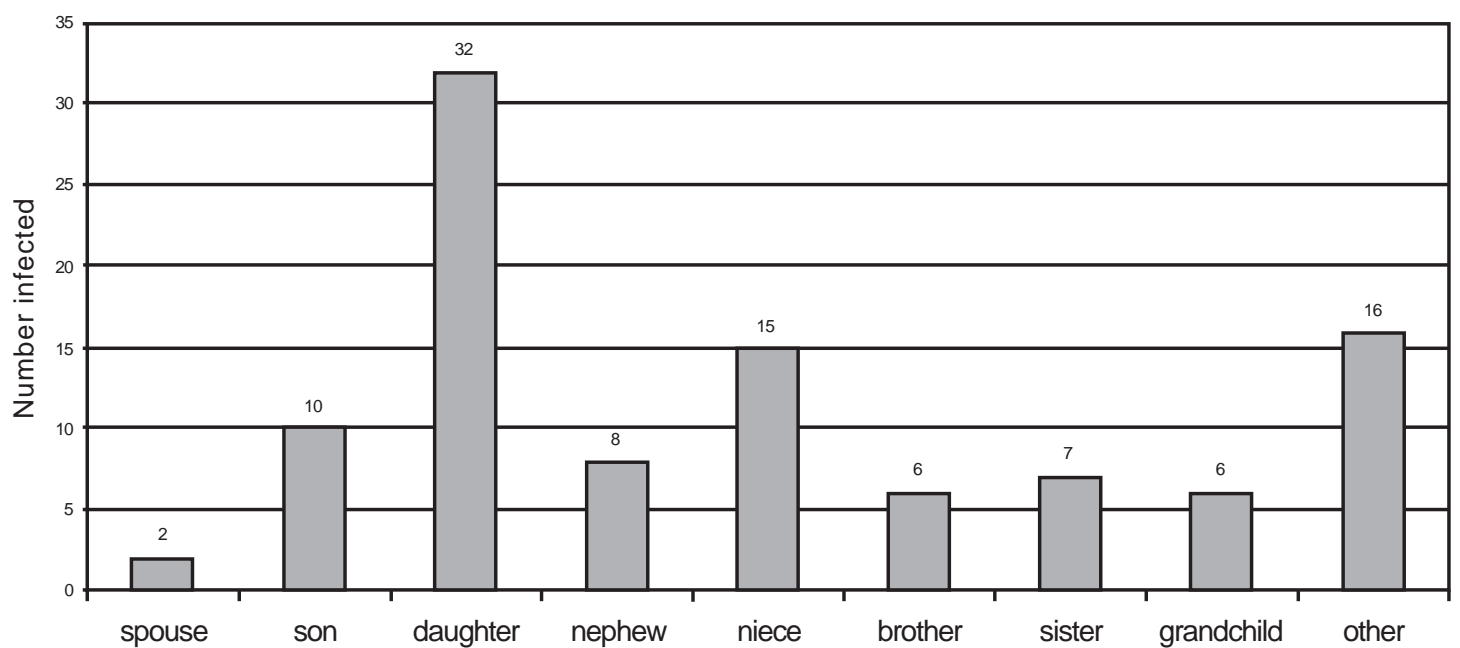

Fig. 3. Grandmothers' family members who were HIV positive.

- Income generation - 'How to make extra income'.

- Peer support - 'Co-operation and love brings success.'

\section{WHAT WAS THE BEST THING ABOUT BEING IN A GROUP?}

Participants' responses fell into the following categories:

- Stress alleviation - 'We have a chance to relieve stress.'

- Income generation - 'Financial security because of the sewing.'

- Companionship - 'Not sitting at home being unhappy and alone.'

- Safety - 'You feel free to communicate your feelings to other people.'

- Problem solving - 'Problems regarding HIVIAIDS are shared'.

\section{WHAT WAS THE WORST THING ABOUT BEING IN A GROUP?}

Ninety percent of the respondents said that there was nothing negative that could be said about being in a group. Those who did report something negative generally complained about arguments within the group and (in 2 cases) about the unfair distribution of goods within the group.

\section{COMMUNITY INTERVENTION BY GRANDMOTHERS}

The responses to the question 'How can you help people who have HIVIAIDS in their families?' fell into the following categories:

- Referral - 'by referring them to the nearest group of GAPA'

- Tolerance - 'by asking them to accept the child so that he/she can accept the disease'. 
- Education - 'to teach them how to look after people who have AIDS and not just to throw them away'.

- Destigmatisation - 'Teach them not to hide it, look after herself honestly. This is not the end of the world.

- Practical help - 'I can help the person to bath the HIVpositive person, I can cook for them and comfort them.

- Counselling - 'counselling, giving hope, it's not the end of the world to be HIV-positive.'

\section{THE MONTHLY INDABAS}

Every month from July 2004 to December 2004 all members of GAPA were invited to attend an indaba at the GAPA centre in Khayelitsha. The average monthly attendance was 90 grandmothers. The programme of the gathering followed a similar format each month. It included a talk about HIV/AIDS by one of the group leaders, prayer and song, and an hour during which grandmothers were invited to address the group about what belonging to GAPA meant to them. By giving them an open topic to talk about, the researchers discovered what the grandmothers felt to be most important issues in their relationship with GAPA. Their testimony was recorded and transcribed from isiXhosa into English for later analysis. The testimony by individual grandmothers caused the atmosphere of the gathering to be emotionally charged and there were frequent outbursts of crying and wailing by grandmothers who were overcome by emotion. After each grandmother's testimony there would a short spiritual song or a prayer by the whole group. These sessions were therapeutic for the individual speaking out as well as for others who could relate to their stories.

The data gathered were rich and multitudinous. The researchers sorted the data into broad categories based on issues that were repeatedly brought up when the grandmothers were addressing those present at the indabas. Their testimony dealt with subjects such as their health and their interactions between their families and their communities. Direct quotes from what the grandmothers said at the indabas capture the essence of what they considered to be the most important issues surrounding the AIDS epidemic and their interaction with GAPA.

\section{GRANDMOTHERS' HEALTH}

Many of the grandmothers said that being left on their own to cope with death and illness in the family caused them to suffer from stress and ill health.

'Before I heard that my daughter was HIV positive I had nothing wrong with my health. No high blood pressure, no diabetes, but when she fell sick with TB and I was told it was $H I V$, I was devastated, I became sick myself. When I met the people who were attending the GAPA group I felt better. Even when she died leaving a 5-year-old baby I was stronger than before.'

\section{FAMILY DYNAMICS}

Grandmothers spoke of being isolated from their communities because of the stigma associated with the unknown. In some cases grandmothers revealed that their family members had kept their conditions secret and denied being infected even though they were very ill.

II am very thankful to GAPA. Where would we be today without these groups? We are here because of our children. They are driving us crazy. I don't have a good life myself. My grandson is on drugs. Always he steals everything he sees. At the same time my daughter is sick with HIV but does not want to accept. I am so glad that Mrs F has given us this opportunity to share our burdens and get support from you. With the help and support of GAPA I am sure I will be able to survive difficulties and help my daughter come back to her senses.'

The value of being in a support group was described as providing education about the disease and providing emotional support which gave them strength to speak openly about AIDS.

'It is good to talk about HIV to protect it from being a scary thing.'

'Our lives have been touched by GAPA. It taught us to accept HIV as other diseases. I am staying at home with my daughter who is HIV+ but sometimes forgets she has that disease. That is the way GAPA made me accept HIV. I am at peace with the disease.'

Grandmothers who received preschool fees for their grandchildren expressed relief that children who otherwise would be kept at home had somewhere safe to go to during the day.

'We have grandchildren with whom we were sitting alone at home. I am no longer with sorrows because my granddaughter is at preschool paid for by GAPA.'

'Now my grandson attends a preschool and is paid for by GAPA because I don't have any money to pay for him.'

\section{INTERACTION WITH OTHERS IN THE GROUP}

Some grandmothers described how when a GAPA group leader invited them to join a support group in their area they went along to the group with scepticism. However they soon realised the benefits of the knowledge, understanding and emotional support they received from their peers. Joining the psychosocial groups gave them a feeling of togetherness and acceptance with others in their group.

'When I entered Mrs M's house (group leader) I could feel the acceptance in the women that she was working (sewing) with. Now even if people talk about AIDS I no longer get 
anxious thinking that they mean the AIDS in my family. I have learned to accept all situations and sicknesses through GAPA.'

Furthermore, they learned new practical skills such as sewing and gardening. They were very proud to discover that they were able to make useful household articles that they could sell or use in their own homes. Planting their own vegetables was also a source of pride to them.

'I gained a lot from GAPA. I now eat vegetables, cabbage and spinach grown in my garden.

\section{CONCLUSION}

Results of this research project are very encouraging and show conclusively that GAPA is making a positive contribution to the lives of grandmothers and their families. The information that grandmothers receive in workshops, from group leaders and their peers equips them with some practical skills to cope with their daily lives. Food gardens have been started, financial aid in the form of government grants has been accessed, handicraft groups have been started to increase household income, and small children have been sent to preschool. Grandmothers have found strength from one another to speak out about the stigma that existed around families that had HIV-positive members, and have been able to lean on each other in times of family deaths and crises. GAPA has bred a group of grandmothers who are well informed and concerned for their families and communities in an atmosphere of ignorance and fear of HIV/AIDS. Grandmothers indicated time and again that with one another's support they were willing to share knowledge with their communities. Furthermore, they acknowledged that a problem shared became less of a problem and resolved to encourage families to disclose their HIV status so that they too could benefit from community support.

To sum up, HIVIAIDS is killing the younger people of South Africa and it is the grandparents who will be left with much of the burden of bringing up future generations of South Africans. The problem has been succinctly put by a grandmother at an indaba:

'Elderly women are crying on their own with no one to talk to. It has turned from them expecting to be buried by their children, now elderly women bury their children. That is not nice, we need to comfort each other under this umbrella (GAPA).'

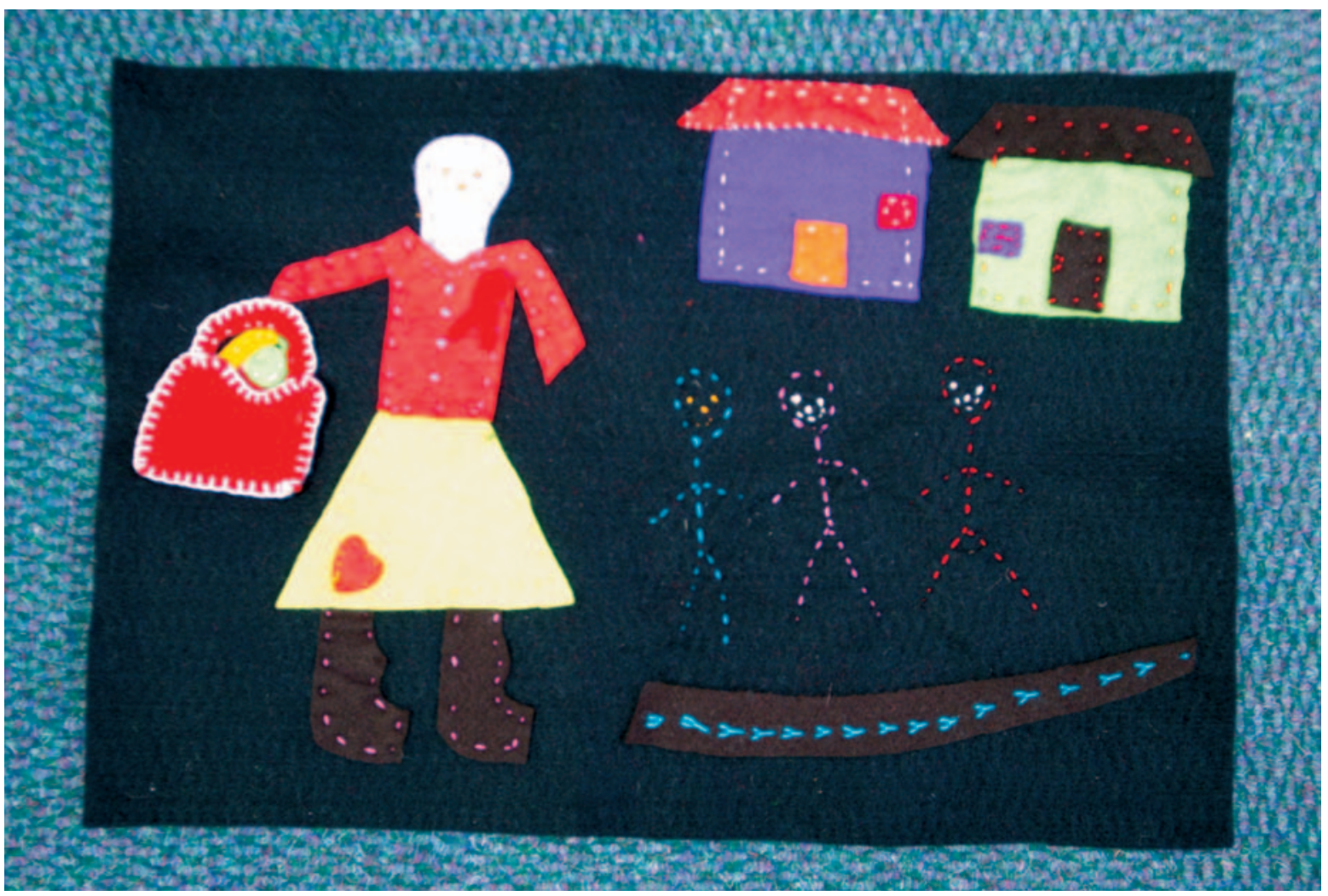

